JOSE MANUEL MORELOS VILLEGAS

UNIVERSIDAD DE CALDAS

CALDAS, COLOMBIA.

INSTITUTO DE ARTES PLÁSTICAS

UNIVERSIDAD DE VERACRUZ

VERACRUZ, MÉXICO.

JOSEMAMORELOS@YAHOO.COM.MEX

\section{El cartel político en México: memoria, reflexiones e inflexiones}

Political poster in Mexico: memory, reflections and inflections

Resumen. Establecer una clasificación irreductible de los tipos de cartel es una empresa imposible, debido a que este ente creativo crea sus categorías en su devenir performativo y social. En el presente ensayo se hace un reconocimiento de su complejidad interpretativa, en su multiplicidad de valores y se insiste en la necesidad de establecer iniciativas de resguardo de los carteles de contenido político en México a fin de contener una memoria y patrimonio social e ideológico para la reconstrucción de la identidad, con vistas a su estudio e interpretación.

Palabras clave: cartel, cartel político mexicano, identidad, memoria, patrimonio.

Abstract. Establishing an irreducible classification of poster typologies is an impossible undertaking because this creative entity establishes its categories in its performative and social evolution. This essay recognizes its interpretive complexity in its multiplicity of values and insists on the need to establish initiatives to protect political content posters in México in order to contain a memory and social and ideological heritage, for identity reconstruction, with a view to their study and interpretation.

Keywords: heritage, identity, Mexican political poster, poster, memory.

Este artículo es producto de la investigación realizada para la tesis doctoral del autor (Morelos Villegas, 2016).

Fecha de recepción: 14/07/2017

Fecha de aceptación: 25/09/2017

Cómo citar: Morelos Villegas, J. M. (2017)

El cartel político en México: memoria,

reflexiones e inflexiones. RChD: creación y

pensamiento, 2(3), 1-10.

DOI: $10.5354 / 0719-837 \times .2017 .47824$

Revista Chilena de Diseño,

RChD: creación y pensamiento

Universidad de Chile

2017, 2(3)

http://rchd.uchile.cl 
El cartel político es un hijo de la calle, de estridente voz en off, lacia y diáfana mirada, que navega entre los océanos de la ética y la estética, de lo íntimo a lo público, lo profesional a lo amateur, sobre la espuma de la utopía.

JOSÉ M. MORELOS

\section{Introducción}

Estos dispositivos cartel, afiche, póster, plakat, cartello... Más allá de los idiomas, al margen de etimologías y taxonomías, conducen a un mismo objetivo: comunicar; poner "en común algo a alguien" en un espacio temporal. La actividad que implica es proyectual, es prefiguración y configuración creativa y funcional. Los concursos internacionales de cartel los categorizan en tres grandes apartados: cultural, político-social y comercial. No obstante, es impensable una clasificación total en torno a este ente creativo, debido a que sus categorías corresponden a un diverso ámbito performativo, cultural, histórico, político, social, tecnológico e histórico.

Poesía visual, retoño de su tiempo y de sus necesidades de comunicación; producto de la encomienda o iniciativa propia -un llamado, susurro de la conciencia social-. Adagio del "Aquí y ahora" que nos habla desde nuestro propio hablar, de manera sintética e inverosímil en ideas y economía de recursos visuales. Evoca, convoca y provoca; denota y connota; anuncia y denuncia; conmemora y rememora; conmina y conmueve. El cartel implica emisor y receptor; ícono y logos; texto y cotexto; fenómeno y noúmeno; mímesis y diégesis.

El cartel desde su inmanencia, arrojado al mundo de la vida, el Lebenswelt de Husserl (1992), poiesis, retórica (figuras, tropos), la epidermis de los muros en el contexto urbano o en forma de bits, afronta y confronta los molinos de la ética y la estética, el ser y el existir. Lo anterior expresado en comunión con sus indistintas estéticas: del encargo, de la conciencia social, de lo popular, de la emergencia, del poder y de la disidencia; el diseño, artes plásticas, mercadotecnia, propaganda; lo profesional y lo amateur, etcétera.

Coexisten disímiles miradas que comulgan en la periferia del cartel; entre ellas, la que propone interpretarlo por sus valores conceptuales, gráficos, técnicos y funcionales; teorías de la comunicación, significación, percepción, alfabetidad visual, reproductibilidad y sistemas de impresión; y la que lo ausculta a partir de la metáfora de la cebolla de Lacan (cit. por Singer), en donde su identidad deja paso a su identificación y a la vez se pierde para sí mismo, o a la voluntad de su creador y transita hacia la especulación e interpretación del otro. De ahí que devenga en indistintos juicios o valores estéticos: El Mar es el mar... el Cartel es el cartel. Y el cartel político en México, sobre todo a lo largo del siglo XX, es sin duda una de las más importantes expresiones de la presencia y del disenso social. Su acervo, preservación y difusión constituyen dispositivos indispensables para una ética de la memoria.

\section{Metodología}

En las siguientes páginas, se expone un acercamiento al ejercicio del cartel político desde lo ontológico, su valor y su función como creador de memoria. El propósito de estas reflexiones, en las que de forma intencional y lúdica se enfrentan términos opuestos para caracterizar las múltiples aristas y facetas de mi objeto de estudio, es abordar y entretejer la práctica del cartel 
como un ente complejo, estética y visualmente, pero también cargado de significaciones que como archivo de memoria es una inagotable fuente de conocimiento, especialmente el cartel político-social. Se acotan algunas manifestaciones de este tipo en México y su importancia en la conformación de identidad y como patrimonio de la cultura mexicana.

Canal popular de la cultura de las masas y la modernidad abierta desde lo privado a lo público; del "evangelio del éxito" (García Nossa, cit. por Sabogal). Hecho ético y estético que emerge de enunciados lingüísticos a visuales para acortar el plazo temporal entre un acontecimiento social o comercial y su conocimiento. Acto nemotécnico, esquina para los encuentros y desencuentros entre el sujeto y el predicado, la verdad y el poder, el tiempo y el espacio, el diseño y su función, y, donde se desdibujan las fronteras entre el aviso, el diseño y el arte. Alegorías culturales que facilitan la participación del sujeto social con los colectivos y el imaginario colectivo. Artefactos fronterizos que generan conocimiento y autorreconocimiento, interacción y configuración simbólica del Yo, el Ello, el Self, en relación con lo Otro.

Concomita presencia y nemotecnia, la existencia, representación, vigencia, reforzamiento y recordación de ese "algo". Simbiosis de códigos culturales, semánticos, morfológicos y lingüísticos; ideas, conceptos, investigación, documentación, convergen con expresiones simbólicas, experiencias estéticas, habilidades técnicas, estilos, color, volumen, texturas, tipografías, quirografías, tecnografías y métodos de reproducción que se cristalizan en una pieza, a manera de dípticos, trípticos, polípticos, murales, vallas o repeating posters. Dispositivo didáctico formativo e informativo empleado para la enseñanza en los distintos niveles y áreas del conocimiento, impresos en papel o en diversos sistemas analógicos y digitales, como el e-poster. Para la práctica de la mercadotecnia, publicita un producto o servicio, genera su necesidad, incita a su consumo basándose en sus características, acciones directas e indirectas, con una iconografía objetiva o subjetiva (subliminal). En lo relativo a la propaganda, es una importante arma mediática para la divulgación de ideologías (políticas, religiosas o militares).

A diferencia de otras áreas del arte, el cartel no es una "obra abierta" como gusta de afirmar Umberto Eco; es más bien una obra cerrada, unívoca e irrepetible en conceptos, mas no en su reproductibilidad y distribución. Su esencia radica en la transmisión de un mensaje con un lenguaje directo, elocuente y pertinente, de fácil lectura y asimilación para efectos de persuasión y pregnancia. Misión y visión que deben estar libre de añadiduras o falsas interpretaciones para el destinatario común o público meta (target).

Los estilos, técnicas de representación visual, tipografías, formatos y tecnologías... no hacen del cartel un cartel y sí otra cosa. Es el bien decir, en la mirada del Otro la que lo legitima y justifica su existir; es la mirada del Otro, la que hace del cartel un cartel y no otra cosa; cuando ahonda, toca las fibras del individuo y se reconoce en esa voz, en ese sentir, el punctum de Barthes. $Y$ es, en ello, donde reside la elocuencia de su existir: es una forma de ver y mirar el mundo. El cartel no pertenece al autor, "al artista de la libertad condicionada", acotaría Josep Renau, sino a quien lo hace suyo y se lo apropia: el cartel es de quien lo necesita.

\section{Algunos valores del cartel}

Las teorías del valor distinguen el valor de uso del valor de cambio. La idea más generalizada es la que propone que el valor de uso es el que se le otorga 
al objeto de acuerdo con su utilidad. En lo tocante al cartel su reto tácito es comunicar, es un valor de uso inmediato. Empero, caducado su propósito informativo se resignifica y connota en un valor del coleccionismo, ya sea histórico, temático, autoral, por sus valores gráfico-plásticos o eclécticos. De hecho, hay carteles que no se usan en un sitio público, sino en la intimidad del hábitat, como objeto decorativo, conmemorativo, como fetiche o testimonio en tanto documenta acontecimientos o acciones realizadas. Entretanto, el valor de cambio interpreta el objeto como una mercancía susceptible de ser cambiada (o comprada), y se ciñe al pago en moneda, a una transacción mercantil. Este complejo tema del sistema de valores que pasa revista a diversos autores puede ser atribuible al cartel. Al respecto Baudrillard (1972) introduce los valores: de símbolo y de signo.

- El valor simbólico, de gran valor sentimental o emocional de un objeto para una determinada persona, es independiente del valor monetario (de cambio) y de uso, por ello se dice que es irreemplazable.

- El valor de signo gravita en torno a las percepciones sociales a partir de lo que representa o sustituye (elemento, fenómeno, acción material), rasgos de identidad, pertenencia, estatus (social, económico o intelectual); refiere a lo que el objeto significa en un determinado contexto.

De lo anterior se desprende el valor político, vinculado a conceptos de distinta índole, sobre todo en los carteles que surgen de manera contestataria al poder, como un vehículo para su denuncia, el reclamo por acontecimiento que atañe a la sociedad en su conjunto. En tiempos de sufragio popular, para la estructura del marketing político es recurrente y profuso su empleo (cartel electoral) para cautivar el voto; funge como un importante dispositivo de presencia y de identificación con el candidato, un receptáculo para las filias, promesas y desafíos. A estas funciones se le suma al cartel su valor como objeto de devoción, como fetiche. No precisamente el que se colecciona para hacer acopio de un conjunto ordenado de carteles, sino aquel en que el sujeto "de afecto" es representado, con el gesto, los signos o los símbolos que comportan o transmiten una narración entre la imagen y el espectador para crear puentes que asocian tendencias, gustos y admiraciones a un género artístico (el gig poster), las imágenes de culto religioso, la esfinge del gobernante en turno, entre otros paradigmas. En lo tocante a otras líneas interpretativas, no podemos soslayar el cartel fotográfico con la sensual imagen de la mujer, típica en talleres mecánicos o bodegas de materiales para la construcción, que convierten al cartel en objeto de culto, en una suerte de parafilia para satisfacción y deseos del ego; algunos como calendarios para efectos de alargar su vida y por tanto la promoción de la marca. Piénsese también en los carteles que apelan por ayuda ante la pérdida de una mascota, manifestaciones, costumbres de la cultura popular y la forma de consumirla que a ojos de los ortodoxos del cartel y la academia no son reconocidos como tales. No obstante, con mayor o menor fortuna estética (valores gráficos), forman parte de nuestro paisaje urbano, manufacturados en diversos formatos, reproducidos a color o en blanco y negro. El contenido conmueve más que el continente, es decir, son más "estéticos" en el sentido de despertar una emoción o un sentimiento. Y no se diga el de los padres que buscan a su hijo, el de los desaparecidos o presos políticos, entre otros temas. Habría que mencionar, además, la imagen del cartel que hace las veces de un objeto de culto, de conexión simbólica, de algo que contrarresta la ausencia. Como el que reproduce una obra de arte de la exposición vigente y se exhibe para su venta como un producto del merchandising, donde el 


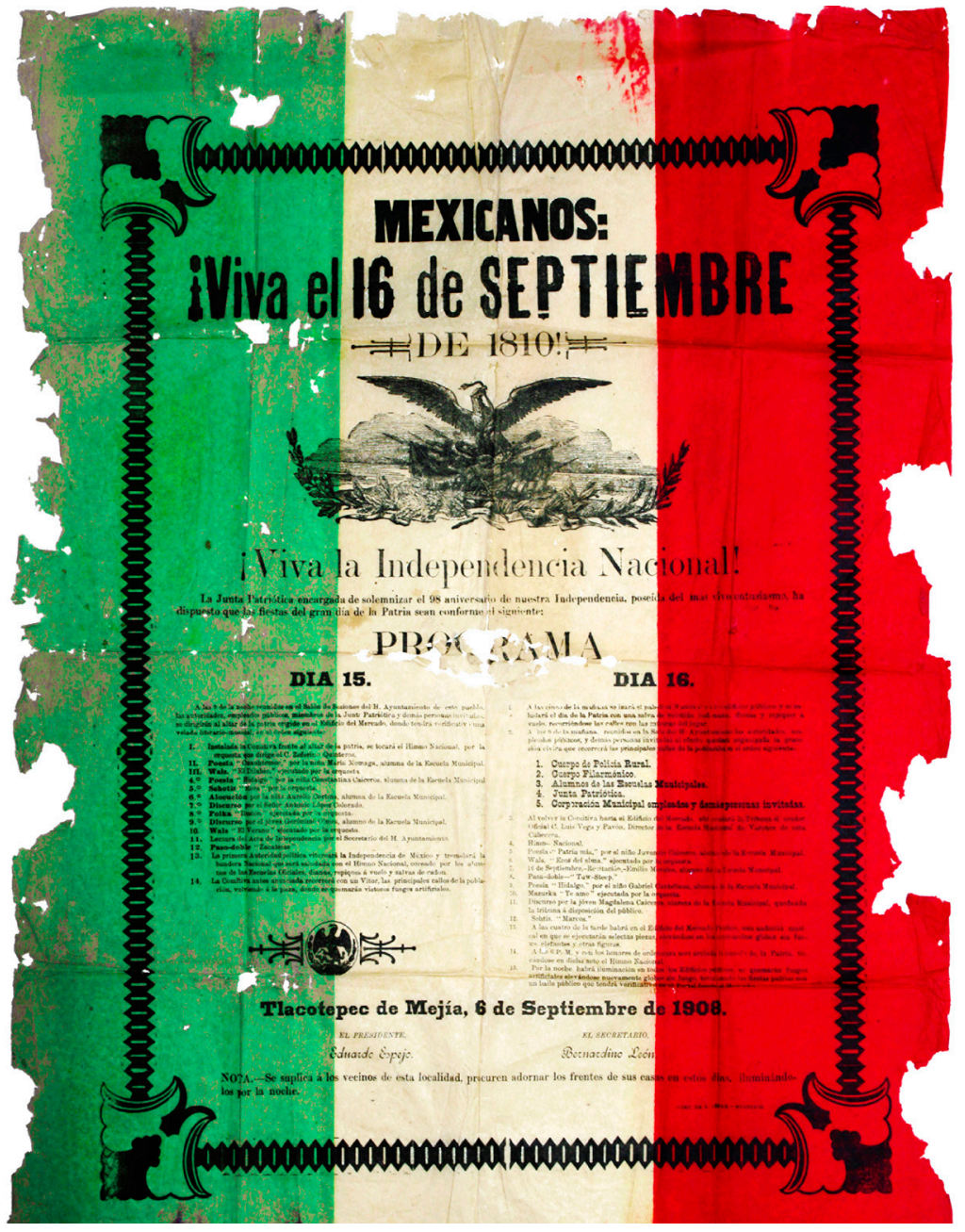

cartel sustituye a la obra original para el que lo adquiere, como testimonio y reafirmación de que se estuvo ahí. El cartel colgado en la intimidad del hogar hace las veces de una credencial de estatus social e intelectual, revela el sentido de pertenencia, delimita fronteras o el deseo de formar parte de algo a lo que se le otorga suma importancia.

Como se ha referido, el cartel puede ser analizado y caracterizado a través de diversos valores, así como también justipreciado como obra de arte, en tanto que tasa expresiones, conceptos, técnicas, estilos, corrientes y configuraciones propias de las artes plásticas. Y se constituye en "categoría" de obra de arte cuando lo oficializa e institucionaliza el poder vía sus mecanismos (galerías, museos, concursos nacionales e internacionales, compradores, subastas, coleccionistas). Para el autor del cartel este puede tener un uso más: una obra que puede exhibirse con otras dentro de los espacios de poder de las artes.

\section{El cartel político en México como memoria, patrimonio e identidad}

Canto de sirenas, mosaico de connotaciones, sistemas de valores y alusiones públicas. Epopeya de un pueblo y elemento de la sociología de las creencias que da fe de sus hitos, mitos, fetiches, usos-costumbres, preocupaciones y aspiraciones. Extensión del pensamiento cuya fisicidad
Figura 1. ¡Viva la independencia nacional!, Anónimo, 1908. Fuente: Archivo José M. Morelos. 

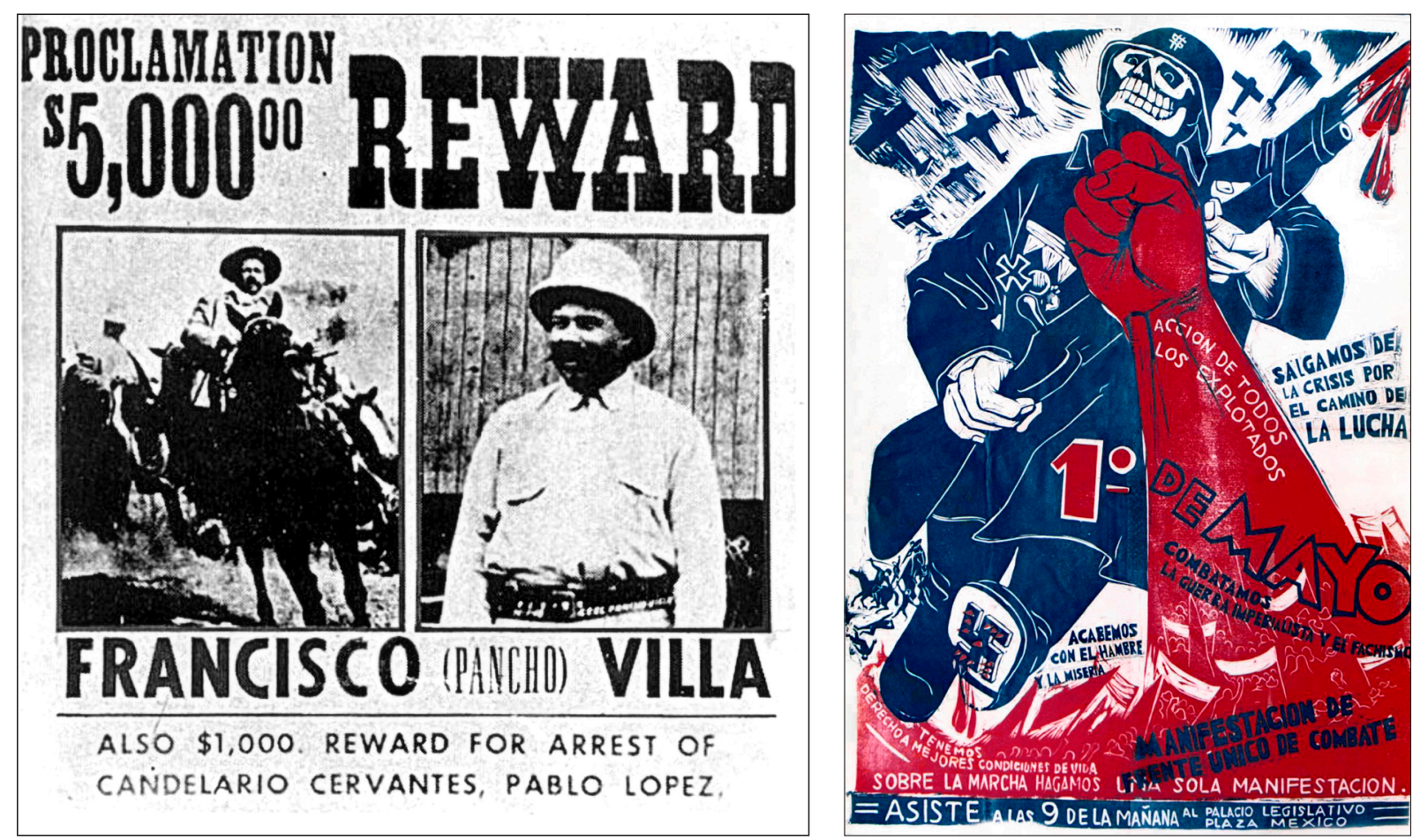

Figura 2. Reward Francisco (Pancho) Villa, Anónimo, 1916. Fuente: Dominio Público.

Figura $3.1^{\circ}$ de Mayo Combatamos la guerra imperialista y el fachismo, Anónimo, s/f. Fuente: Archivo Centro de Estudios del Movimiento Obrero Socialista (CEMOS). y naturaleza (physis), residen en el deber ser de las cosas (deóntico) en comunión con el bien decir (grafía) en un lugar y tiempo (endémico). Medio masivo al servicio del capital y su contraparte, donde convergen y hacen catarsis las miradas, las sociopolíticas de los sentimientos, demandas y arengas sociales, protagonistas y antagonistas. Termómetro de las sociedades, instrumento de control social al servicio de los músculos del poder para su acceso, legitimización y conservación.

Los carteles políticos en México son documentos gráfico-históricos valiosos en su conjunto, por lo diverso y representativo en las diferentes épocas en que destaca su producción en el siglo XX, previo y posterior a la Revolución mexicana (1910), y con mayor profusión hacia las décadas posteriores. Entre las temáticas que abordan los carteles de los años treinta a los cincuenta destacamos brevemente los realizados, en apoyo a la Guerra Civil Española, contra el nazismo y el fascismo, la participación de México en la Segunda Guerra Mundial, el respaldo a la Unión soviética, en repudio a la intervención de Estados Unidos en países centroaméricanos, en apoyo a las luchas mineras, campesinas, ferrocarrileras y magisteriales, entre otros contenidos, y donde la presencia del Taller de la Gráfica Popular (TGP) es de suma importancia, por lo que ha sido merecedor de numerosos estudios.

La década de los sesenta irrumpe con los movimientos sociales que convulsionaron al mundo, y dados los acontecimientos de décadas anteriores en México, el cartel continuó testimoniando la represión, los personajes presos y los desaparecidos políticos, el Movimiento Médico (1964), entre otros hitos. Sentimientos, covulsiones sociales que se verán reflejados prolíficamente alrededor de la gráfica emergente y contestataria del Movimiento Estudiantil del 68, y que por ser México sede de la XIX Olimpiada alcanzaría una resonancia internacional. 

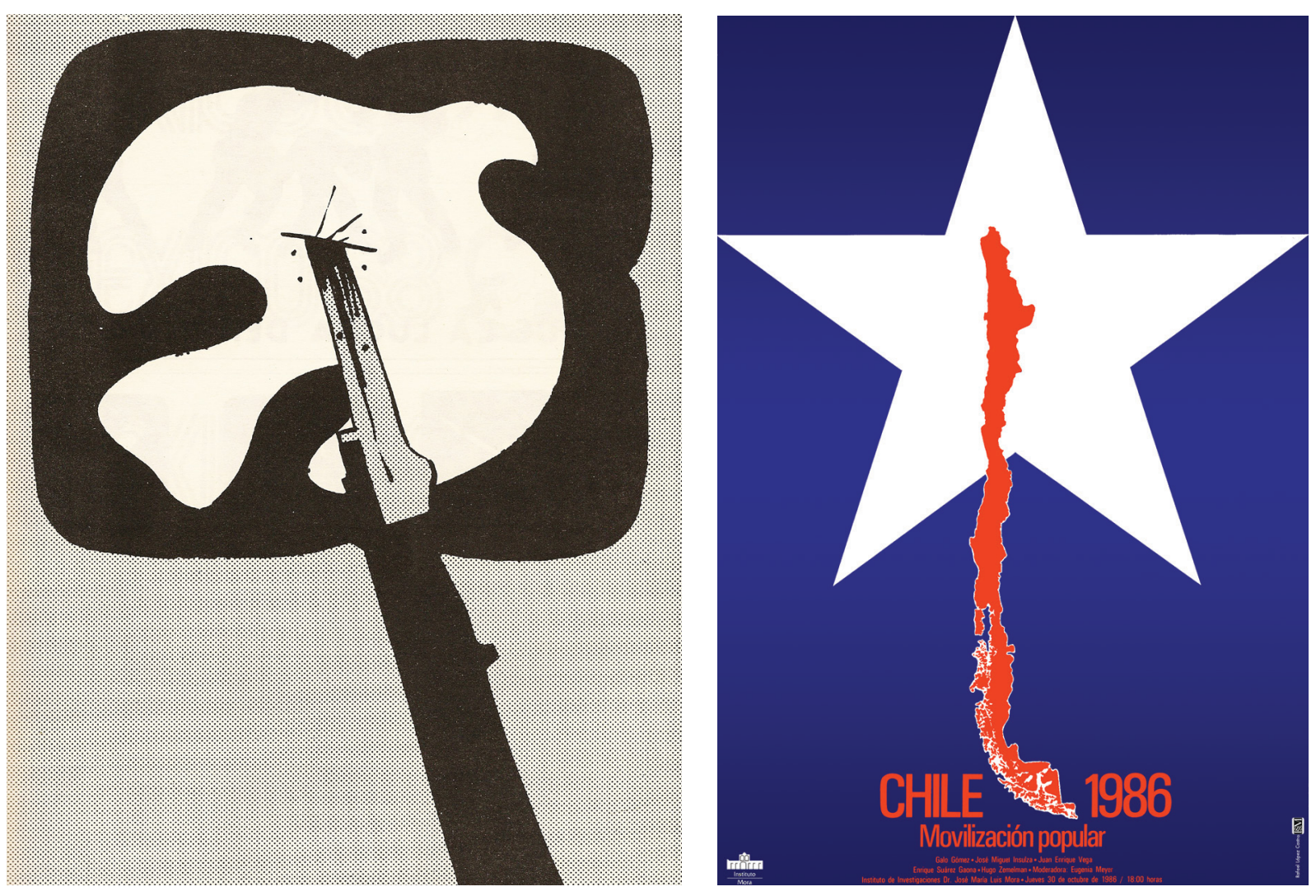

Acontecimiento de frontera entre una década y otra. $Y$ de lo que el cartel también es memoria es de la "guerra sucia", emprendida por el Estado mexicano contra grupos radicales desde mediados de la década; en los setenta, con las muestras de solidaridad a países latinoamericanos y en contra de las dictaduras en el Cono Sur, Vietnam, entre otros tópicos; para los ochenta, haría lo propio testimoniando la crisis ecónomica, en apoyo a la tragedia del sismo en Ciudad de México (1985); a las luchas sindicales, protestando por la controvertida elección presidencial (1988). Vale la pena acotar en este apartado que los partidos de izquierda, al carecer de recursos y acceso a otros medios de comunicación, ponderaron al cartel como un bien común para la propagación de sus ideologías. En principio -y previo a la concepción del profesional en diseño como tal- los carteles fueron realizados por artistas, dibujantes, arquitectos, entre otros, que por miltancia o simple simpatía con el movimiento -y casi siempre sin recibir pago alguno- crearon piezas de una gran riqueza conceptual y gráfica. Ya para los noventa los partidos de izquierda obtienen más recursos y la accesibilidad a otros medios de comunicación, su propaganda, la comisionan a las agencias de publicidad y en lo que respecta al diseño de cartel, sin mayor trascendencia y emotividad. En 1992 y con el marco de los preparativos para conmemorar el descubrimiento o "invención de América”, el cartel ofrece un punto de vista crítico, y con mayor presencia en 1994 al entrar en vigor el Tratado de Libre Comercio de America del Norte (TLCAN), y como respuesta a lo anterior, la irrupción del Ejército Zapatista de Liberación Nacional (EZLN) en las montañas del sureste mexicano. Registró el fin de la hegemonía del Partido
Figura 4. Paloma de la paz atravesada por bayonetas, Jesús Martínez, 1968. Tomado de La gráfica del 68. Homenaje al Movimiento Estudiantil, 1993. Figura 5. Chile 1986, Movilización popular, Rafael López Castro,1986. Fuente: Archivo del autor. 
12 DE OCTUBRE DE 1992 A 500 AÑOS DE LA INVASION SEGUIMOS RESISTIENDO PORQUE:
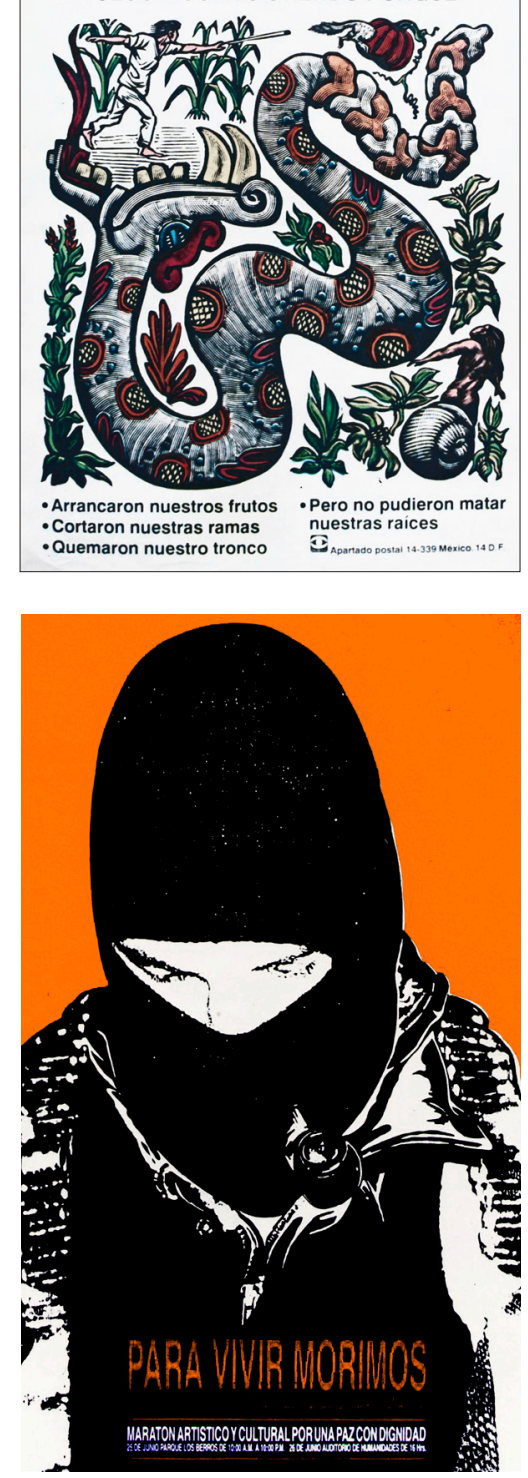

Figura 6.12 de octubre de 1992. Fuente: Archivo del Centro Libre de Experimentación Teatral y Artística (CLETA).

Figura 7. Para vivir morimos, José M. Morelos, 1994. Fuente: Archivo de José M. Morelos.
Revolucionario Institucional (PRI) en las elecciones del 2000, tras 70 años en el poder; en 2010 hizo lo propio a manera de festejo o crítica por las conmemoraciones del bicentenario de la Independencia y centenario de la Revolución mexicana. En años recientes el cartel repudiando la violencia desatada en México, denunciando la desaparición de los estudiantes de Ayotzinapa, y así un largo etcétera.

El cartel político no busca, encuentra a sus interlocutores y los disuade de una verdad encadenada a una no-verdad que, desde la concepción nietzscheana, es conquista del poder y su voluntad: voluntad de poder que, parafraseando a José Pablo Feinmann (2012), la verdad está encadenada a una no-verdad que, desde la concepción nietzscheana, es conquista del poder y su voluntad, en tanto que el poder sujeta la subjetividad del sujeto. Voluntad de poder y del poder ser de las cosas que se manifiestan en ese pedazo de papel, de realidad -en el sentido positivista del término-, y que lo patentan en un poder en sí mismo, el poder de la comunicación: la persuasión. Implica parábolas de acento propio, espejo para el autorreconocimiento y la dignidad, en tanto que él se dignifica y resignifica en la medida que se hace dueño de lo público. Son vidas encapsuladas en ideas, conceptos y creaciones que emergen por el principio de la causalidad, como respuesta a un fenómeno político-social desde la anarquía de la espontaneidad, emocionalidad, subversión o sedición; soledad, impotencia, esperanza y desolación.

Locus social endógeno y exógeno, estandarte para la disidencia, el consenso y el disenso, las conquistas del poder y su contraparte: "donde hay poder hay resistencia", sentenciaría Foucault (1984). Actores principales que permiten trazar un paralelo para la gestación y articulación de su discurso político-visual: el cartel patrocinado por el poder y el de sus antagonistas. Grupos y sujetos sociales marginados del poder, sin rostro, quienes, al no tener acceso a otros medios de comunicación, expropian el cartel como un bien común, una propiedad intelectual, el pensamiento crítico y reclamo social a la autoridad. Es una forma de lucha y resistencia contra la injusticia, la ignominia y el olvido del poder, en tanto hace visible lo invisible, nombra lo innombrable; a manera de panóptico observa sin ser observado.

Nos dice René Char (cit. por Roca): "La historia es el reverso del traje de los amos". Tenemos una historia individual y una colectiva que casi nunca se entreteje con los hilos del poder; por tanto, no existe una sola verdad, no hay una historia completa. El cartel político pertenece al mundo de los hechos, del eidos de Platón; es un momento único e irrepetible que narra, de voz en voz y en tercera persona, una gran historia que está a la espera de ser escuchada, leída y razonada.

Si el hombre es un animal simbólico en tanto portador de sentido (Cassirer, 1967) y las imágenes son historias, una vez claudicada la función comunicativa del cartel se aposta en la memoria para modelar el pasado. Construye y reconstruye episodios de la vida nacional e internacional que lo configura en monumentum, memoria eidética para el reconocimiento y autorreconocimiento, la narración del tejido social y sus relaciones físicas y morales. Estructuras significativas que dotan de sentido histórico-político a una civilización, y donde la narración es la primera parte para la construcción y reconstrucción de una memoria colectiva e universal.

Sobre la premisa de que somos lo que somos, porque somos lo que hemos vivido, y que los pueblos son su memoria, el cartel político adquiere mayor pertinencia y significancia como testimonio para el reconocimiento de los 
hechos político-sociales y la construcción de una memoria histórica-política-gráfica colectiva, puesto que un cartel, a manera de instrumento arqueológico, connota una realidad, es un metalenguaje, muestra más de lo que nos dice. Son imágenes que van a la imaginación del transeúnte para establecer un diálogo, pactar, recrear y alojarse en el imaginario colectivo, la memoria de una comunidad, una nación, en la memoria del mundo. Colectivizar el pasado desde la creación de espacios simbólicos, cápsulas para la memoria, lugares de archivo, sistemas de enunciabilidad (Foucault, 1979) proyectados desde una política de inclusión y resiliencia, es un acto de reivindicación, reparación simbólica y justicia social contra el almanaque del olvido. La memoria comunal es compromiso con la dignidad, un derecho ético y estético para la reconstrucción moral e histórica de identidad y patrimonio cultural. La construcción de una memoria colectiva, un palacio de la memoria, al servicio de lo público; articulada desde el cartel político, es una reconciliación con la vida; permite la dignificación del individuo para consigo mismo y la humanidad.

\section{Conclusiones}

Cartel político, obrero de las ideas, protagonista asiduo de grandes revueltas sociales que merece ser compilado, estudiado y justipreciado como patrimonio cultural de una sociedad y para la humanidad. Hacer la arqueología del cartel político es construir la historiografía que expresa una dialéctica del individuo con la sociedad y construye significados. Hacer de un recuerdo un lugar físico y espacial, legitima la historia del individuo y de su cultura. Afirma y confirma identidades, filias y diferencias, y en su reconocimiento, al decir de Heidegger, surge la identidad. Es un Ilamado a la conciencia individual y colectiva, un aliento de solidaridad con nuestro pasado. Recupera horizontes de sentido, eslabones perdidos, pensamientos, sueños y anhelos de libertades conculcadas, todo ello desde ese grito en la pared, ese pedacito de papel que hoy es historia. En consecuencia, es preciso conservar estas piezas, soportes para el pensamiento y el sentir de un pueblo. El patrimonio que constituye el cartel es conocimiento que puede ser albergado y cobijado en la academia, al ser las instituciones universitarias entidades capaces de garantizar la libertad de expresión y de pensamiento, si bien es cierto que "La verdadera libertad no consiste en poder decir lo que se piensa, sino en poder pensar lo que se dice" (Antonio Machado).

Cartel político, catalizador de sentimientos, cronista de su tiempo, notario de la historia, prólogo de otros prólogos, etnografías del poder y los Otros. Oxímoron ideológico, laberinto de quimeras, esquizofrenia de formas y colores, radiografías sociales indispensables para comprender esa metáfora que es el México de los últimos siglos. 


\section{Referencias}

Barthes, R. (1982). La cámara lúcida. Barcelona: Gustavo Gili.

Baudrillard, J. (1972). Crítica de la economía política del signo. Buenos Aires: Fondo de Cultura Económica.

Cassirer, E. (1998). Filosofía de las formas simbólicas. México: Fondo de Cultura Económica.

Eco, U. (1990). Obra abierta. Barcelona: Ariel.

Feinmann, J. P. [Archivo de vídeo] (2012, 8 de abril).

Filosofía aquí y ahora - Nietzsche: vida y voluntad

de poder. Recuperado el 1.06.2017, de https://www. youtube.com/watch? $\mathrm{v}=\mathrm{nPi} \mathrm{sU}_{3} \mathrm{~K}_{5} \mathrm{eo}$

Foucault, M. (1979). La arqueología del saber. México: Siglo XXI.

Foucault, M. (1984). Vigilary castigar. Nacimiento de la prisión. Bogotá: Siglo XXI.

Heidegger, M. (1990). Identidad y diferencia. Barcelona: Anthropos.

Husserl, E. (1992). Invitación a la fenomenología. Barcelona: Paidós.

Morelos Villegas, J. M. (2016). El cartel político como memoria, identidad y patrimonio de la cultura mexicana, propuesta para su documentación, preservación y conservación (Tesis de Doctorado) Universidad de Caldas, Colombia.

Renau, J. (1976). Función social del cartel. Valencia: Fernando Torres.

Roca, J. M. (2015). Tríptico de la infamia. Una coreografía de sombras. Recuperado el 1.07.2016 de www.jornada.unam.mx/2015/07/05/sem-juan.html

Sabogal, J. (2003). Antonio García Nossa, un pensador latinoamericano. Utopía y Praxis Latinoamericana, Año 8 abril-junio, 73-85. Recuperado el 3.06.2017 de http:// www.redalyc.org/pdf/279/27902106.pdf

Singer. F. (1993) La problemática de la normatividad en psicoanálisis. El aporte de J. Lacan.Temas de Psicoanálisis, diciembre, 1993. Montevideo. 